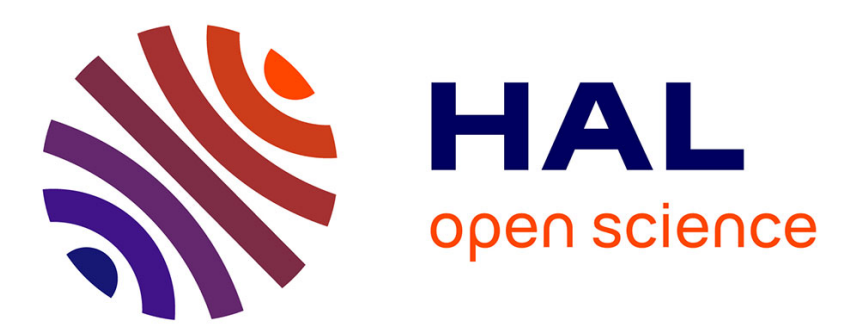

\title{
Behaviour Modelling of Two Aluminas in Divergent Spherical Pyrotechnical experiments
}

F. Malaise, J.-Y. Tranchet, Francis Collombet

\section{To cite this version:}

F. Malaise, J.-Y. Tranchet, Francis Collombet. Behaviour Modelling of Two Aluminas in Divergent Spherical Pyrotechnical experiments. Journal de Physique IV Proceedings, 1997, 07 (C3), pp.C3-681C3-686. 10.1051/jp4:19973116 . jpa-00255401

\section{HAL Id: jpa-00255401 https://hal.science/jpa-00255401}

Submitted on 1 Jan 1997

HAL is a multi-disciplinary open access archive for the deposit and dissemination of scientific research documents, whether they are published or not. The documents may come from teaching and research institutions in France or abroad, or from public or private research centers.
L'archive ouverte pluridisciplinaire HAL, est destinée au dépôt et à la diffusion de documents scientifiques de niveau recherche, publiés ou non, émanant des établissements d'enseignement et de recherche français ou étrangers, des laboratoires publics ou privés. 


\title{
Behaviour Modelling of Two Aluminas in Divergent Spherical Pyrotechnical experiments
}

\author{
F. Malaise, J.-Y. Tranchet and F. Collombet* \\ Centre d'Études de Gramat, 46500 Gramat, France \\ * LAMEF-ENSAM, Esplanade des Arts et Métiers, 33405 Talence cedex, France
}

\begin{abstract}
Two pure aluminas of different characteristics have been subjected to the propagation of a longitudinal divergent spherical shock wave through pyrotechnical experiments. An approach combining a phenomenological analysis and numerical 1D-calculations is proposed to study the beliaviour of these aluminas submitted to that type of wave loading. The modelling, proposed in a previous paper, is refined and gives satisfying experimentationcalculation correlations. An analysis of the infuence exerted by the various encountered phenomena (plastic activity, pore closure, microcracking) is performed. The significant consequence of the activation of damage with an extension criterion is also underlined.
\end{abstract}

\begin{abstract}
Résumé. Des essais pyrotechniques permettant de soumettre un matériau à la propagation d'une onde longitudinale sphérique divergente ont été réalisćs sur deux alumines pures de caractéristiques différentes. Une approche combinant analyse phénoménologique et calculs numériques ID est proposée pour étudier le comportement de ces alumines soumises à ce type de sollicitation. La modélisation proposée lors d'une précédente publication est affinée et permet d'obtenir des corrćlations expérience-calcul satisfaisantes. L'analyse de l'influence des divers phénomènes rencontrés (activité plastique. fermeture des pores, fissurations) est effectuée. L'inportance de l'activation d'un endomnagernent à partir d'un critère en cxtension est soulignée.
\end{abstract}

\section{INTRODUCTION}

This study takes part in the process engaged to model the response of ceramic materials under shock wave loading. More exactly, the goal of this paper is to model the mechanisms (plasticity, pore closure or microcracking) generated by the propagation of a divergent spherical shock wave, and their time evolution. The studied materials are two pure aluminas, AL23 and T299, with different average sizes of grains [1]. The Divergent Spherical Pyrotechnical (DSP) experiments, part of the experimental techniques developed by the Centre d'Etudes de Gramat to study dynamic behaviour of materials, are used to characterise the behaviour of these aluminas under divergent spherical shock wave loading [1]. Unlike others studies [2], the post-mortem observation of the soft-recovered samples, and the measurements of the particle velocity or stresses as a function of time, are performed from two distinct experimental set-ups [1].

The physical information collected are limited as the post-mortem observation gives any information related to the final state of the materials but none concerning the evolution of the local mechanisms. In addition, the macroscopic response of the material is locally measured and is influenced by the history of all the events encountered between the detonation and the measurement points.

A phenomenological analysis performed from the available experimental data is the foundation of the theoretical selections made in modelling. A model of generalised plasticity is used to account for the effects of pore closure on the material behaviour. The influence of pore and crack presence on the elastic behaviour of the material is considered through a homogenisation technique. Comparatively to precedent papers [3], several improvements are proposed for the representation and evolution of the damage states due to microcracking. In particular, a damage criterion in extension is introduced in the modelling. The modelling selections are validated or not by comparing the experimental particle velocity (or radial stress) time histories to the numerical ones computed with a one-dimensional wave propagation code. 


\section{PHENOMENOLOGICAL ANALYSIS}

The main point of the phenomenological analysis have been presented in previous studies [1] [4] [5] Taking into account the eventuality of damage evolution by extension of the materials despite a tricompression stress state [6] refines this analysis. The loading associated to the crossing of the divergent spherical wave is divided into three successive phases.

During the first phase of loading, the strain state is uniaxial (no extension). A microplastic activity appears and contributes to collapse the initial pores. The Hugoniot Elastic Limit defines the threshold from which the microplasticity influences the macroscopic response of the material [1]. More, the association of the highly triaxial stress state to the probable blocking of dislocations at grain boundaries generates local shear stresses [7] that contribute to nucleate intergranular microcracks. Owing to the intensity of the applied confinement, the microcracks remain closed and do not operate on the macroscopic behaviour of the material. The divergent nature of the spherical shock wave leads to an intensity decrease of both mechanisms (plasticity, microcracking) with the distance $r$ to the explosive.

During the second loading phase, a state of biextension perpendicularly to the wave propagation direction lets the microcracks previously nucleated open. This microcracking, mainly observed close to the explosive, does not present a privileged orientation.

At last, during the third loading phase, the material is subjected to tensile hoop stresses. Far from the explosive, these stresses generate a network of transgranular microcracks oriented in the wave propagation direction.

Observations have also emphasised an intermediary area where the networks of oriented and nonoriented microcracks are both present.

\section{MODELLING}

The high number of mechanisms, which influence actually the macroscopic response of the material, in addition to the complexity of the loading sequences lead us to select a modular modelling of the aluminas behaviour. Thus, the effects of microplastic activity and pore closure are represented through a model of generalised plasticity. The influences of pore or crack presence on the mechanical elastic characteristics of the material are modelled via a homogenisation technique used for heterogeneous and disordered media. Nucleation and propagation of microcrack networks are modelled with semi-empirical evolution laws for void volume fractions.

\subsection{Plasticity and pore closure}

The plasticity criterion is defined by the equation of the yield surface proposed by Gurson [8]:

$$
\mathrm{F}\left(\mathrm{S}_{\mathrm{ij}}, \mathrm{P}, \Phi\right)=\frac{3}{2} \mathrm{~S}_{\mathrm{ij}} \mathrm{S}_{\mathrm{ij}}+\mathrm{Y}_{\mathrm{m}}^{2}\left(2 \Phi \mathrm{q}_{\mathrm{l}} \cosh \left(\frac{-3 \mathrm{q}_{2} \mathrm{P}}{2 \mathrm{Y}_{\mathrm{m}}}\right)-\mathrm{l}-\mathrm{q}_{1}^{2} \Phi^{2}\right)=0
$$

where $P$ is the pressure, $\Phi$ the porosity, $S_{i j}$ the deviatoric part of stress tensor, $Y_{m}$ the yield stress of the reference dense material (Lucalox); $\mathrm{q}_{1}, \mathrm{q}_{2}$ are correcting parameters introduced by Tvergaard [9].

The isotropic work-hardening of the reference dense material is described using a Ludwig-type law that depends on the cumulated plastic strain $\gamma^{p}$ :

$$
Y_{m}=Y_{0 s}+C_{2}\left(\gamma^{p}\right)^{n}
$$

where $Y_{0 s}$ is the initial yield stress of Lucalox, $C_{2}$ and $n$ the work-hardening parameters [5]. 


\subsection{Damage}

\subsubsection{Semi-empirical evolution laws}

Modelling the evolution law of the void volume fraction (associated to nucleation and growth of microcracks) is performed through the introduction of semi-empirical evolution laws that, unlike in [5], depend on the extension and/or tensile state imposed to the material.

3.2.1.1 Nucleation law of the isotropic damage : during the first loading phase, the damage is passive [3]. A nucleation law is used to determine the evolution of the number of microcracks generated during loading. This evolution varies as a function of the equivalent plastic strain $\gamma^{p}$ [2] [7]. The variable $D_{N}$ characterises the material state during this phase and is defined by the following equation :

$$
D_{N}=\operatorname{Min}\left(\frac{k_{1}\left(\gamma^{p}-\gamma_{0}^{p}\right)^{m}}{N_{\max }}, 1\right)
$$

where $\gamma_{0}{ }^{p}$ is the nucleation threshold, $k_{1}$ and $m$ the parameters of the nucleation law, $N_{\max }$ the number of facets of the alumina grains which are assumed to be dodecahedron.

The material is assumed to be fragmented when $D_{N}$ is equal to 1, i.e. the number of nucleated microcracks is equal to the number of grain facets per volume unit.

3.2.1.2 Criterion and evolution law of the isotropic damage in extension state : in the following, the activation threshold of this isotropic damage is defined by the value of the equivalent extension at spalling $\varepsilon_{S P}^{*}\left(\varepsilon^{*}\right.$ is an equivalent variable positively defined in extension $\left.{ }^{1}[10]\right)$. Above this limit, the void volume fraction $f_{i}$ (related to the growth of the non-oriented microcracks) increases according to the incremental following law:

$$
d f_{i}=D_{\varepsilon} \exp \left(-D_{\varepsilon}\left(\varepsilon^{*}-\varepsilon_{s p}^{*}\right)\right) d \varepsilon^{*}
$$

where $\mathrm{D}_{\varepsilon}$ is the parameter of the isotropic damage in extension.

The threshold $\varepsilon_{\text {SP }}^{*}$ decreases linearly as a function of the nucleation variable $\mathrm{D}_{\mathrm{N}}$.

3.2.1.3 Criterion and evolution law of the isotropic damage in tensile state : when the material is fragmented $\left(D_{N}=1\right)$, only the void volume fraction $f_{i}$ evolves as a function of the equivalent tensile stress $\sigma^{*}$ (a tension variable similarly defined to the variable $\varepsilon^{*}$ ). When a component of the stress tensor becomes negative (tension), $\mathrm{f}_{\mathrm{i}}$ increases according to the incremental law :

$$
\mathrm{df}_{\mathrm{i}}=\mathrm{D}_{\mathrm{i} \sigma} \exp \left(-\mathrm{D}_{\mathrm{i} \sigma}\left(\sigma^{*}-\sigma_{\mathrm{sp}}^{*}\right)\right) \mathrm{d} \sigma^{*}
$$

where $D_{i \sigma}$ is the parameter of the isotropic damage in tension.

3.2.1.4 Criterion and evolution law of the anisotropic damage in tensile state : when the material is not fragmented $\left(D_{N}<1\right)$ and when the equivalent tensile stress $\sigma^{*}$ becomes higher than the equivalent stress at spalling $\sigma^{*}{ }_{\mathrm{sp}}$, then only the void volume fraction $\mathrm{f}_{\mathrm{a}}$ (relative to nucleation and growth of the oriented microcracks) increases according to the incremental law :

$$
\mathrm{df}_{\mathrm{a}}=\mathrm{D}_{\mathrm{a} \sigma} \exp \left(-\mathrm{D}_{\mathrm{a} \sigma}\left(\sigma^{*}-\sigma_{\mathrm{sp}}^{*}\right)\right) \mathrm{d} \sigma^{*}
$$

where $D_{a \sigma}$ is the parameter of the anisotropic damage in tension.

${ }^{\prime} \varepsilon^{*}=\sqrt{\left(\varepsilon_{\mathrm{ij}}\right\rangle^{2}}$

where $\left\langle\varepsilon_{i j}\right\rangle=\varepsilon_{i j}$ if $\varepsilon_{i j}<0$ (extension)

otherwise $\left\langle\varepsilon_{\mathrm{ij}}\right\rangle=0$ (contraction) 


\subsubsection{Representation of the damaged state}

The elasticity-operator components $M_{i j k l}$ of the porous and/or damaged material depend on the isotropic elastic moduli of the reference dense material, on the macroscopic variables $\left(\Phi, f_{i}\right.$ and $\left.f_{a}\right)$, and on the nature of the flaws. The effect of pores or microcracks on the macroscopic elastic response of the material is evaluated through a homogenisation technique [11] and the following calculations :

- calculation of the initial material characteristics for a volume concentration $\Phi$ of spheroidal voids that are randomly distributed and randomly oriented in the reference dense material,

- calculation of the isotropically damaged material characteristics for a volume concentration $f_{i}$ of "penny-shaped" voids that are randomly distributed and randomly oriented in the initial material,

- calculation of the anisotropically damaged material characteristics for a volume concentration $\mathrm{f}_{\mathrm{s}}$ of "penny-shaped" voids that are oriented in the wave propagation direction and randomly distributed in the isotropically damaged material.

\section{RESULTS AND DISCUSSION}

Two different pure aluminas whose main characteristics are listed in Table 1 have been tested. The particle velocities and the radial stresses have been measured respectively with a Doppler Laser Interferometer and $\mathrm{Mn} / \mathrm{Cn}$ piezoresistive gauges [1]. Figure 1 shows the particle velocity time histories measured at the interface between the AL23 alumina (three samples of different thicknesses are tested) and polymethylmethacrylate (window material) [1]. Figure 2 presents the radial stress time histories recorded by $\mathrm{Mn} / \mathrm{Cn}$ gauges located at three different abscissas in a T299 alumina sample. The analysis of the T299 profiles (Figure 2) is limited to the rising parts because of the uncertainties associated to the determination of the gauges characteristics during the release phases.

The diameter of the alumina cylinders is sufficient to prevent lateral release waves from disturbing measurements. In such conditions, the divergent spherical wave is assumed to have a one-dimensional propagation and a WONDY-type code [12] is used to simulate the explosive detonation and the wave propagation in the material.

A parametric study is performed to determine the model parameter values that give the best corrrelations between experimentation and calculation. These values are listed in Table 1 .

Table 1 : Characteristics of the studied materials and parameter set.

\begin{tabular}{|l|c|c|}
\hline Bulk density & AL23 alumina & T299 alumina \\
\hline Porosity $(\%)$ & $3.8-3.92$ & 3.86 \\
\hline Average grain size $(\mu \mathrm{m})$ & $1-4$ & 3 \\
\hline Hugoniot Elastic Limit $(\mathrm{GPa})$ & $20-70$ & $2-7$ \\
\hline Tvergaard parameter $\mathrm{q}_{1}(\mathrm{~S} . \mathrm{I})$ & $6.5-7.1$ & 8.3 \\
\hline Tvergaard parameter $\mathrm{q}_{2}(\mathrm{~S} . \mathrm{I})$ & 7 & 4.2 \\
\hline Spalling equivalent extension $\varepsilon_{\mathrm{SP}}^{*}(\%)$ & 0.4 & 0.58 \\
\hline Spalling equivalent tensile stress $\sigma_{\mathrm{SP}}(\mathrm{GPa})$ & 0.12 & 0.083 \\
\hline Spalling mean stress $(\mathrm{GPa})$ & 0.54 & 0.38 \\
\hline Nucleation factor $\mathrm{k}_{1}\left(\mathrm{~m}^{-3}\right)$ & -0.27 & -0.18 \\
\hline Exponent of the nucleation power law $\mathrm{m}(\mathrm{S} . \mathrm{I})$ & $2.610^{23}$ & $7.310^{24}$ \\
\hline Number of facets $\mathrm{N}_{\max }\left(\mathrm{m}^{-3}\right)$ & 7 & 7 \\
\hline Isotropic damage factor in extension $\mathrm{D}_{\varepsilon}(\mathrm{S} . \mathrm{I})$ & $5.710^{12}$ & $5.710^{15}$ \\
\hline Isotropic damage factor in tension $\mathrm{D}_{\mathrm{i \sigma}}\left(\mathrm{GPa}{ }^{-1}\right)$ & 0.35 & 0.62 \\
\hline Transversally isotropic damage factor in tension $\mathrm{D}_{\mathrm{a}}\left(\mathrm{GPa}^{-1}\right)$ & 0.5 & 1 \\
\hline
\end{tabular}




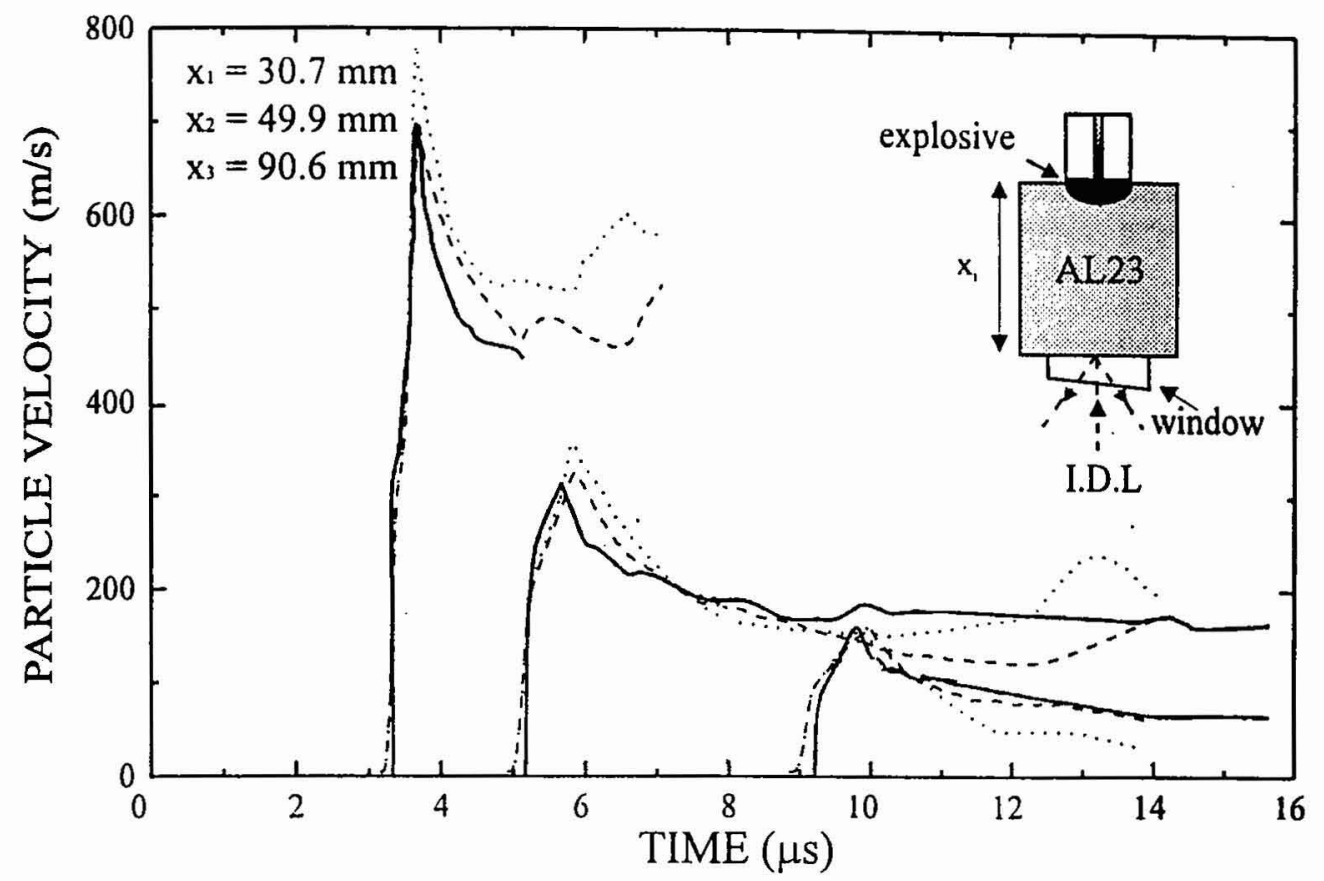

Figure 1 : Comparisons of the experimental data (solid line) and the numerical data calculated with the reference modelling (dotted line) and with the complete modelling (dashed line) for AL23 alumina.

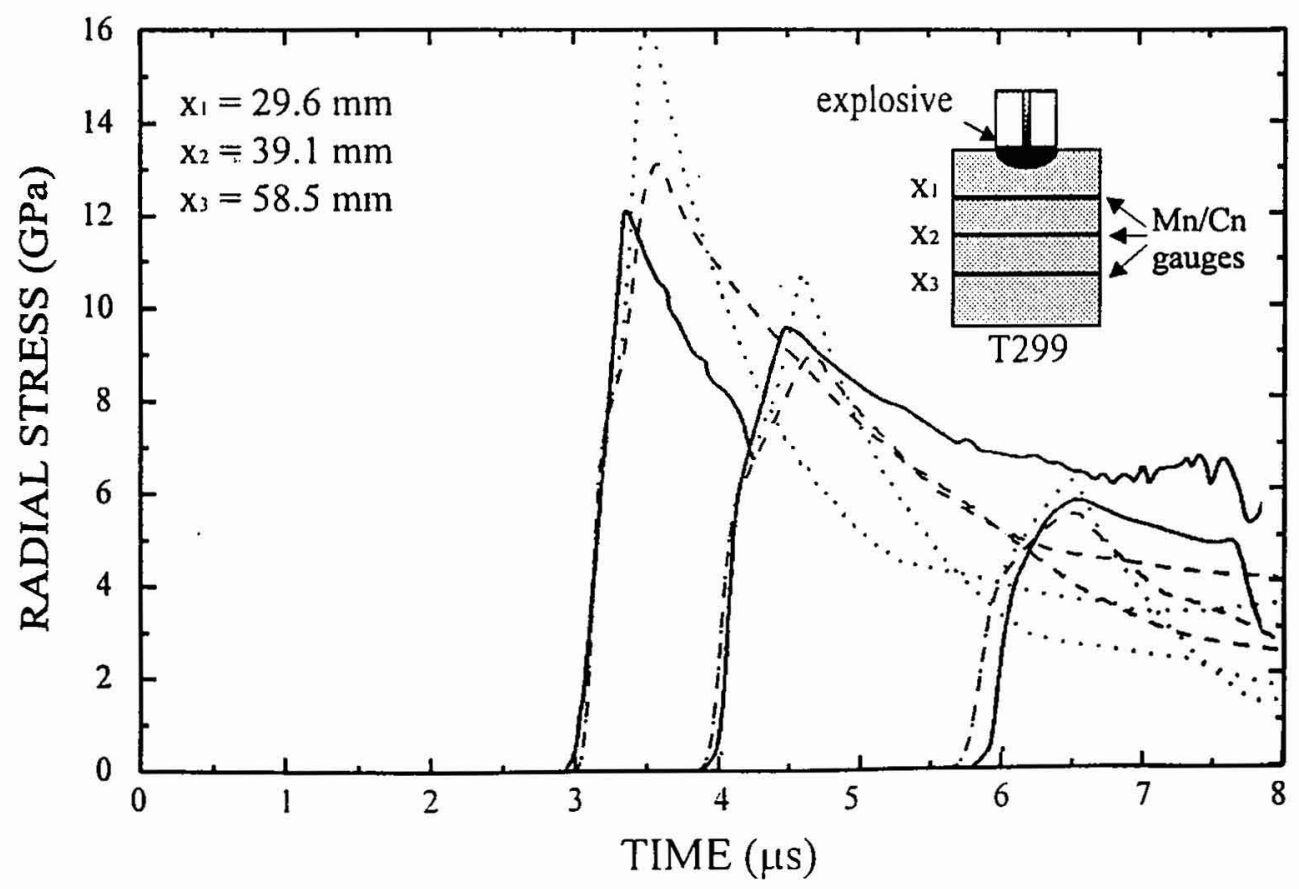

Figure 2 : Comparisons of the experimental data (solid line) and the numerical data calculated with the reference modelling (dotted line) and with the complete modelling (dashed line) for T299 alumina. 
A model based on the plasticity criterion defined in section 3 and a simple rupture criterion in tension is used as a reference model. The rupture threshold chosen is the mean stress at spalling. Figures 1 and 2 show the experimental wave profiles and those calculated with the reference models and with the complete models at several Lagrangian abscissas in aluminas.

The profiles of Figures 1 and 2 present the typical triangular feature that corresponds to the crossing of a divergent spherical wave. The Lagrangian analysis points that the rising parts of the signals (shock) correspond to the first phase and the beginning of the second phase of the loading sequence described in section 2. The decreasing parts (release) correspond to the end of the second phase and to the third phase [13]. Thus, the rupture criterion associated to the reference model is only satisfied during release.

For AL23 alumina, the reference model cannot predict the particle velocity maxima recorded for the two nearest abscissas to the explosive. On the other hand, the value of the farthest Lagrangian abscissa is correctly calculated. The rupture criterion permits to reproduce approximately the feature of the particle velocity time histories during release.

For T299 alumina, a significant discrepancy is put forward between the radial stress maxima calculated with the reference model and the measured ones : this discrepancy decreases with the distance to the explosive. The delay observed between the calculated and measured wave arrival times for the farthest abscissa from the explosive could be due to the thicknesses of gauges between the alumina cylinders.

The complete model provides satisfying correlation between calculations and experiments for both materials. The activation of an isotropic damage in compression by means of an extension criterion induces the calculation of the right velocity and stress maxima. In addition, the use of an anisotropic damage model dealing with rupture in tension improves appreciably the reproduction of the release parts of the velocity time histories (AL23) recorded far from the explosive. The use of constant pseudo-viscosity parameters seems to result in the diffusion observed in the farthest time histories from the explosive.

\section{SUMMARY}

A modelling of the behaviour of two aluminas has been proposed. This modelling takes into account the effects of plasticity, pore closure and microcracking. Satisfying comparisons have been drawn between the one-dimensional calculations and the experimental records obtained with DSP experiments. The role of each phenomenon has been discussed owing to the modular nature of the modelling. The results of that analysis emphasise the interest of the activation and propagation of damage from a threshold in extension. A more detailed analysis of the numerical results will be the subject of a further paper [14].

\section{Acknowledgements}

The authors thank Dr P.L. Hereil for his help in implementing the plasticity model in the 1D-code

\section{References}

[1] Cagnoux J., Cosculluela A., Gème Journée Nationale DYMAT, Gramat, France, 1990.

[2] Klopp R.W. et al., Mechanical Testing of Ceramics and Ceramic Composites, Vol 197, ASME, 1994.

[3] Collombet F., Tranchet J.Y., J. de Phys. IV, C8, Vol. 4, 1994.

[4] Cosculluela A., $\mathrm{PhD}$ thesis, Bordeaux I, ${ }^{\circ}$ 695, France, 1992.

[5] Tranchet J.Y., PhD thesis, Bordeaux I, n 1031, France, 1994.

[6] Scholz C.H.. "Rock strength under confined shock conditions", SSS-R-83-5906, Oct.1982.

[7] Lankford J., J. Mat Sci, 12, pp. 791-796, 1977.

[8] Gurson A.L., J. Eng. Mat. Tech., Trans. ASME, 99, 2, 1977.

[9] Tvergaard V., Int. J. Fract., Vol 17, pp. 389-407, 1981.

[10] Collombet F., PhD thesis, Paris VI University and L.M.T., E.N.S. de Cachan, France, 1985.

[11] Tandon G.P., Weng G.J., Composites Science and Technology, Vol 27, pp. 111-132, 1986.

[12] Hereil P.L., CEG report, to be published, 1997.

[13] Cagnoux J.et al., CEG report n T85-24, 1985.

[14] Collombet F., Tranchet J.Y., Malaise F., to be submitted, 1997. 